\title{
Modification of Hooke's law for multiaxial stress in viscoelastic solids
}

\author{
Janusz Kolenda, Prof. \\ Naval Academy of Gdynia
}

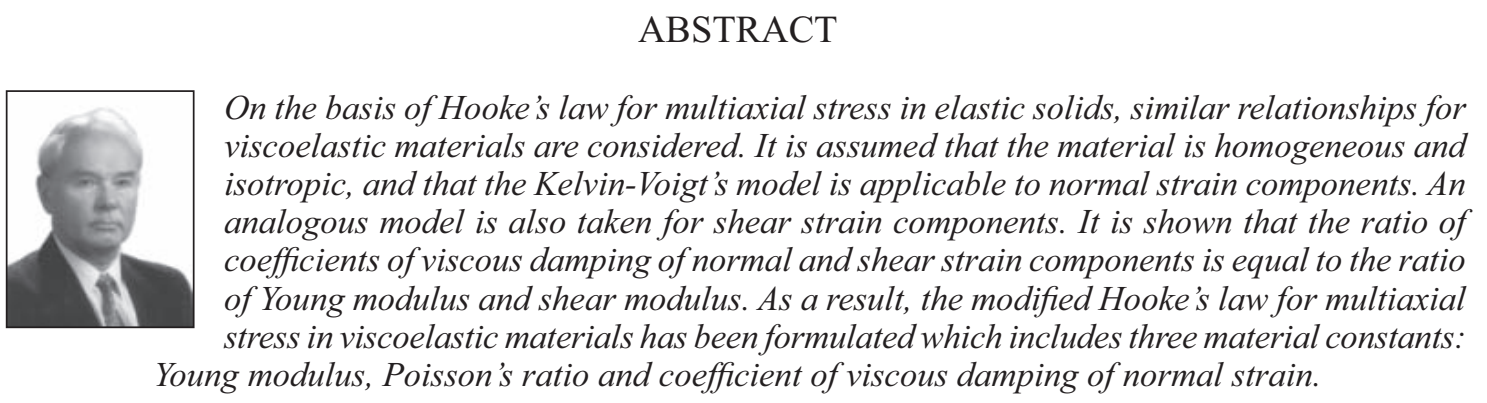

Keywords: Hooke's law, viscoelastic material, Kelvin-Voigt's model, multiaxial loading

\section{INTRODUCTION}

For the purpose of solving physical problems considered in the present paper, it is assumed that an engineering detail is made of a homogeneous isotropic metal and loaded below the yield point. The elastic behaviour of a particular homogeneous, isotropic metal at a given temperature is completely defined by the Young modulus and the Poisson's ratio $[1,2]$. However, even in the region below the proportional limit metals are not perfectly elastic. If a load is suddenly applied and then maintained constant, a small amount of "creep" will always be observed [1]. This creep is due to anelastic strain which may arise from any of several sources, such as the presence of grain boundaries, twin boundaries, or slip bands, the diffusion of interstitial solute atoms and the phenomenon of magnetostriction. Particular attention is focused on anelastic strain in the vibration theory of continuous systems [3, 4]. To exemplify the problem, let us mention that contrary to free vibrations of perfectly elastic systems where the principle of energy conservation may be assumed, in reality the initial energy of isolated vibrating systems diminishes with time as a result of energy dissipation caused by damping properties of structural materials. This phenomenon is very complex but there are several approximate models of anelastic materials and damping mechanisms which are simple enough to be accepted in practice, for instance the Kelvin-Voigt's model (spring and dashpot in parallel) and hysteretic damping [3-6]. In the present paper, the Kelvin-Voigt's model is applied to viscoelastic materials under three-dimensional loads. The second part of this paper, to be published separately, will be devoted to the applications of relationships contained herein, with an emphasis made on the behaviour of viscoelastic solids under multiaxial loads and dissipation energy.

\section{HOOKE'S LAW}

When structures, machines, and engineering details are in service, they are usually subjected to surface forces or body forces (inertial, gravitational, or electromagnetic) that cause combined stresses in their elements. To completely define an element, it is necessary to specify the components of the stress tensor represented by the array:

$$
\mathrm{T}=\left[\begin{array}{ccc}
\sigma_{\mathrm{x}} & \tau_{\mathrm{yx}} & \tau_{\mathrm{zx}} \\
\tau_{\mathrm{xy}} & \sigma_{\mathrm{y}} & \tau_{\mathrm{zy}} \\
\tau_{\mathrm{xz}} & \tau_{\mathrm{yz}} & \sigma_{\mathrm{z}}
\end{array}\right]
$$

where $\sigma$ are the normal stress components and $\tau$ are the shear stress components on three orthogonal planes passing through the point. If surface couples and body couples may be ignored, the number of independent stress components reduces from nine to six since then $\tau_{\mathrm{xy}}=\tau_{\mathrm{yx}}, \tau_{\mathrm{yz}}=\tau_{\mathrm{zy}}$, and $\tau_{\mathrm{zx}}=\tau_{\mathrm{xz}}$ Consequently, deformation produced by stress components can be completely specified by six strain components: normal ones $\varepsilon_{\mathrm{x}}, \varepsilon_{\mathrm{y}}, \varepsilon_{\mathrm{z}}$ and shear ones $\gamma_{\mathrm{xy}}, \gamma_{\mathrm{yz}}, \gamma_{\mathrm{zx}}$. The Hooke's law states that in elastic solids between these components the following relations hold [7, 8]:

$$
\begin{gathered}
\mathrm{E} \varepsilon_{\mathrm{x}}=\sigma_{\mathrm{x}}-v\left(\sigma_{\mathrm{y}}+\sigma_{\mathrm{z}}\right) \\
\mathrm{E} \varepsilon_{\mathrm{y}}=\sigma_{\mathrm{y}}-v\left(\sigma_{\mathrm{x}}+\sigma_{\mathrm{z}}\right) \\
\mathrm{E} \varepsilon_{\mathrm{z}}=\sigma_{\mathrm{z}}-v\left(\sigma_{\mathrm{x}}+\sigma_{\mathrm{y}}\right) \\
\mathrm{G} \gamma_{\mathrm{xy}}=\tau_{\mathrm{xy}} \\
\mathrm{G} \gamma_{\mathrm{yz}}=\tau_{\mathrm{yz}} \\
\mathrm{G} \gamma_{\mathrm{zx}}=\tau_{\mathrm{zx}}
\end{gathered}
$$



and:

Here E is the Young modulus, $v$ is the Poisson's ratio,

$$
\mathrm{G}=\frac{E}{2(1+v)}
$$

is the shear modulus.

For any combination of loads, there exist at any point three orthogonal planes upon which only normal stress components act. These are the principal stresses, designated in declining order of magnitude: $\sigma_{1}, \sigma_{2}$, and $\sigma_{3}$. Therefore, for the particular case where $\mathrm{x}, \mathrm{y}$ and $\mathrm{z}$ are the principal directions, Eqs (2) yiel:

$$
\begin{gathered}
\mathrm{E} \varepsilon_{1}=\sigma_{1}-v\left(\sigma_{2}+\sigma_{3}\right) \\
\mathrm{E} \varepsilon_{2}=\sigma_{2}-v\left(\sigma_{1}+\sigma_{3}\right) \\
\mathrm{E} \varepsilon_{3}=\sigma_{3}-v\left(\sigma_{1}+\sigma_{2}\right) \\
\gamma_{12}=\gamma_{23}=\gamma_{31}=0
\end{gathered}
$$

From Mohr's stress and strain circles [7, 8] it follows that the maximum shear stress and the maximum shear strain are:

$$
\begin{gathered}
\tau=0.5\left(\sigma_{1}-\sigma_{3}\right) \\
\gamma=2 \varepsilon_{1}
\end{gathered}
$$

The relationship between $\tau$ and $\gamma$ reads:

$$
\mathrm{G} \gamma=\tau
$$

For the given stress state that:

$$
\sigma_{1}=-\sigma_{3}, \sigma_{2}-0
$$

one gets:

$$
\begin{gathered}
\mathrm{E} \varepsilon_{1}=\sigma_{1}-v\left(0-\sigma_{1}\right)=\sigma_{1}(1+v) \\
\tau=\sigma_{1}
\end{gathered}
$$

\section{HOOKE'S LAW FOR VISCOELASTIC MATERIALS}

Let us consider what happens to a long rod of homogeneous isotropic material if a tensile force is applied to the end of the rod in the direction $x$ parallel to its length. Of course, this rod will exhibit a uniform tensile strain $\varepsilon_{\mathrm{x}}$ produced by the stress $\sigma_{\mathrm{x}}$.

For elastic state:

$$
\mathrm{E} \varepsilon_{\mathrm{x}}=\sigma_{\mathrm{x}}
$$

Also, it will be observed that the fractional change in diameter is proportional to the axial strain and such that:

$$
\varepsilon_{\mathrm{y}}=-v \varepsilon_{\mathrm{x}}, \varepsilon_{\mathrm{z}}=-v \varepsilon_{\mathrm{x}}
$$

If the force and, consequently, the stress $\sigma_{x}$ is timedependent:

$$
\sigma_{\mathrm{x}}=\sigma_{\mathrm{x}}(\mathrm{t})
$$

it is assumed that Eqs (12) are also valid, i.e.:

$$
\varepsilon_{y}(\mathrm{t})=-v \varepsilon_{\mathrm{x}}(\mathrm{t}), \varepsilon_{\mathrm{z}}(\mathrm{t})=-v \varepsilon_{\mathrm{x}}(\mathrm{t})
$$

Differentiation of Eqs (14) with respect to time gives:

$$
\dot{\varepsilon}_{\mathrm{y}}(\mathrm{t})=-\mathrm{v} \dot{\varepsilon}_{\mathrm{x}}(\mathrm{t}) \quad, \quad \dot{\varepsilon}_{\mathrm{z}}(\mathrm{t})=-\mathrm{v} \dot{\varepsilon}_{\mathrm{x}}(\mathrm{t})
$$

In order to account for viscoelastic properties of the rod in this case by means of the Kelvin-Voigt's model, Eqs (11) and (12) must be replaced by:

$$
\mathrm{E} \varepsilon_{\mathrm{x}}+\eta \dot{\varepsilon}_{\mathrm{x}}=\sigma_{\mathrm{x}}
$$

$$
\varepsilon_{\mathrm{y}}=-v_{\mathrm{a}} \varepsilon_{\mathrm{x}}, \varepsilon_{\mathrm{z}}=-v_{\mathrm{a}} \varepsilon_{\mathrm{x}}
$$

where $\eta$ is the coefficient of viscous damping of normal strain, and [9]:

$$
v_{\mathrm{a}}=v_{\mathrm{e}}+v_{\mathrm{s}}+v_{\mathrm{c}}
$$

In Eq. (18), $v_{\mathrm{a}}$ is the Poisson's ratio in the case of anelastic strain, $v_{\mathrm{e}}$ is related to elastic deformations, $v_{\mathrm{s}}$ is caused by microslips, and $v_{c}$ reflects the influence of microcracks. If the load is such that the solid remains in elastic state, then:

$$
v_{\mathrm{a}}=v_{\mathrm{e}}=\mathrm{v}, \mathrm{v}_{\mathrm{s}}=\mathrm{v}_{\mathrm{c}}=0
$$

Since experiments show that Eq. (19) corresponds very closely to the behaviour of many solids under small loads [9], in what follows Eqs (12), (14) and (15) will be applied.

Now we shall compute the normal strain in the $\mathrm{x}$-direction caused by normal stresses in the $\mathrm{y}$ - and $\mathrm{z}$-directions, where $\mathrm{x}$, $\mathrm{y}$ and $\mathrm{z}$ are any three mutually perpendicular directions.

For the strain due to $\sigma_{y}$, one gets analogously to Eq. (16):

$$
\mathrm{E} \varepsilon_{\mathrm{y}}+\eta \dot{\varepsilon}_{\mathrm{y}}=\sigma_{\mathrm{y}}
$$

Thus:

$$
v E \varepsilon_{\mathrm{y}}+v \eta \dot{\varepsilon}_{\mathrm{y}}=v \sigma_{\mathrm{y}}
$$

But in this case:

$$
\varepsilon_{\mathrm{x}}=-v \varepsilon_{\mathrm{y}} \quad, \quad \dot{\varepsilon}_{\mathrm{x}}=-v \dot{\varepsilon}_{\mathrm{y}}
$$

so that:

$$
\mathrm{E} \varepsilon_{\mathrm{x}}+\eta \dot{\varepsilon}_{\mathrm{x}}=-v \sigma_{\mathrm{y}}
$$

Similarly, for the stress in the z-direction one obtains:

$$
\mathrm{E} \varepsilon_{\mathrm{x}}+\eta \dot{\varepsilon}_{\mathrm{x}}=-v \sigma_{\mathrm{z}}
$$

Eqs (16), (23) and (24) are linear. These equations and principle of superposition lead to the following equation for the strain in $x$-direction:

$$
\mathrm{E} \varepsilon_{\mathrm{x}}+\eta \dot{\varepsilon}_{\mathrm{x}}=\sigma_{\mathrm{x}}-v\left(\sigma_{\mathrm{y}}+\sigma_{\mathrm{z}}\right)
$$

Equations for the strains in the other directions can be found in the same way.

When $\mathrm{x}, \mathrm{y}$ and $\mathrm{z}$ are the principal directions, Eq. (25) becomes:

$$
\mathrm{E} \varepsilon_{1}+\eta \dot{\varepsilon}_{1}=\sigma_{1}-v\left(\sigma_{2}+\sigma_{3}\right)
$$

For the stress state described by equations:

$$
\sigma_{1}(\mathrm{t})=-\sigma_{3}(\mathrm{t}), \sigma_{2}=0
$$

we have from Eq. (26):

$$
\mathrm{E} \varepsilon_{1}+\eta \dot{\varepsilon}_{1}=\sigma_{1}(1+v)
$$

Now let us assume that for viscoelastic solids loaded below the yield point, the maximum shear stress and strain can be expressed by Eqs (5) and (6), determined for elastic solids.

Differentiation of Eq. (6) with respect to time yields

$$
\dot{\gamma}=2 \dot{\varepsilon}_{1}
$$

Analogously to Eq. (16) for normal strain component, for viscoelastic materials and shear strain component instead of Eq. (7) one can write $[3,4]$ :

$$
\mathrm{G} \gamma+\lambda \dot{\gamma}=\tau
$$

where $\lambda$ is the coefficient of viscous damping of the shear strain.

By Eq. (28):

$$
2 \mathrm{E} \varepsilon_{1}+2 \eta \dot{\varepsilon}_{1}=2 \sigma_{1}(1+v)
$$



form:

Through Eqs (6), (10) and (29), Eq. (31) takes on the

that is:

$$
\mathrm{E} \gamma+\eta \dot{\gamma}=2 \tau(1+v)
$$

$$
\mathrm{G} \gamma+\frac{\eta}{2(1+v)} \dot{\gamma}=\tau
$$

From comparison of Eqs (30) and (33) it is seen that:

$$
\lambda=\frac{\eta}{2(1+v)}
$$

Summarizing, the modified Hooke's law for multiaxial stress in viscoelastic solids can be expressed as:

$$
\begin{gathered}
\mathrm{E} \varepsilon_{\mathrm{x}}+\eta \dot{\varepsilon}_{\mathrm{x}}=\sigma_{\mathrm{x}}-\mathrm{v}\left(\sigma_{\mathrm{y}}+\sigma_{\mathrm{z}}\right) \\
\mathrm{E} \varepsilon_{\mathrm{y}}+\eta \dot{\varepsilon}_{\mathrm{y}}=\sigma_{\mathrm{y}}-\mathrm{v}\left(\sigma_{\mathrm{x}}+\sigma_{\mathrm{z}}\right) \\
\mathrm{E} \varepsilon_{\mathrm{z}}+\eta \dot{\varepsilon}_{\mathrm{z}}=\sigma_{\mathrm{z}}-\mathrm{v}\left(\sigma_{\mathrm{x}}+\sigma_{\mathrm{y}}\right) \\
\mathrm{G} \gamma_{\mathrm{xy}}+\lambda \dot{\gamma}_{\mathrm{xy}}=\tau_{\mathrm{xy}} \\
\mathrm{G} \gamma_{\mathrm{yz}}+\lambda \dot{\gamma}_{\mathrm{yz}}=\tau_{\mathrm{yz}} \\
\mathrm{G} \gamma_{\mathrm{zx}}+\lambda \dot{\gamma}_{\mathrm{zx}}=\tau_{\mathrm{zx}}
\end{gathered}
$$

where:

$$
\mathrm{G}=\frac{\mathrm{E}}{2(1+\mathrm{v})} \quad, \quad \lambda=\frac{\eta}{2(1+v)}
$$
[10].

Another derivation of Eqs (34) and (35) can be found in

Eqs (35) can be rewritten in the following alternative forms:

$$
\begin{gathered}
\mathrm{E} \varepsilon_{\mathrm{x}}+\eta \dot{\varepsilon}_{\mathrm{x}}=\sigma_{\mathrm{x}}-v\left(\sigma_{\mathrm{y}}+\sigma_{\mathrm{z}}\right) \\
\mathrm{E} \varepsilon_{\mathrm{y}}+\eta \dot{\varepsilon}_{\mathrm{y}}=\sigma_{\mathrm{y}}-v\left(\sigma_{\mathrm{x}}+\sigma_{\mathrm{z}}\right) \\
\mathrm{E} \varepsilon_{\mathrm{z}}+\eta \dot{\varepsilon}_{\mathrm{z}}=\sigma_{\mathrm{z}}-v\left(\sigma_{\mathrm{x}}+\sigma_{\mathrm{y}}\right) \\
\mathrm{E} \gamma_{\mathrm{xy}}+\eta \dot{\gamma}_{\mathrm{xy}}=2(1+v) \tau_{\mathrm{xy}} \\
\mathrm{E} \gamma_{\mathrm{yz}}+\eta \dot{\gamma}_{\mathrm{yz}}=2(1+v) \tau_{\mathrm{yz}} \\
\mathrm{E} \gamma_{\mathrm{zx}}+\eta \dot{\gamma}_{\mathrm{zx}}=2(1+v) \tau_{\mathrm{zx}}
\end{gathered}
$$

or

$$
\begin{gathered}
\sigma_{\mathrm{x}}=\frac{(1-v)\left(\mathrm{E} \varepsilon_{\mathrm{x}}+\eta \dot{\varepsilon}_{\mathrm{x}}\right)+v\left[\mathrm{E}\left(\varepsilon_{\mathrm{y}}+\varepsilon_{\mathrm{z}}\right)+\eta\left(\dot{\varepsilon}_{\mathrm{y}}+\dot{\varepsilon}_{\mathrm{z}}\right)\right]}{(1+v)(1-2 v)} \\
\sigma_{\mathrm{y}}=\frac{(1-v)\left(\mathrm{E} \varepsilon_{\mathrm{y}}+\eta \dot{\varepsilon}_{\mathrm{y}}\right)+v\left[\mathrm{E}\left(\varepsilon_{\mathrm{x}}+\varepsilon_{\mathrm{z}}\right)+\eta\left(\dot{\varepsilon}_{\mathrm{x}}+\dot{\varepsilon}_{\mathrm{z}}\right)\right]}{(1+v)(1-2 v)} \\
\sigma_{\mathrm{z}}=\frac{(1-v)\left(\mathrm{E} \varepsilon_{\mathrm{z}}+\eta \dot{\varepsilon}_{\mathrm{z}}\right)+v\left[\mathrm{E}\left(\varepsilon_{\mathrm{x}}+\varepsilon_{\mathrm{y}}\right)+\eta\left(\dot{\varepsilon}_{\mathrm{x}}+\dot{\varepsilon}_{\mathrm{y}}\right)\right]}{(1+v)(1-2 v)} \\
\tau_{\mathrm{xy}}=\frac{\mathrm{E} \gamma_{\mathrm{xy}}+\eta \dot{\gamma}_{\mathrm{xy}}}{2(1+v)} \\
\tau_{\mathrm{yz}}=\frac{\mathrm{E} \gamma_{\mathrm{yz}}+\eta \dot{\gamma}_{\mathrm{yz}}}{2(1+v)} \\
\tau_{\mathrm{zx}}=\frac{\mathrm{E} \gamma_{\mathrm{zx}}+\eta \dot{\gamma}_{\mathrm{zx}}}{2(1+v)}
\end{gathered}
$$

When $\mathrm{x}, \mathrm{y}$ and $\mathrm{z}$ are the principal directions with respects to stress, Eqs (37) become:

$$
\begin{gathered}
\mathrm{E} \varepsilon_{1}+\eta \dot{\varepsilon}_{1}=\sigma_{1}-v\left(\sigma_{2}+\sigma_{3}\right) \\
\mathrm{E} \varepsilon_{2}+\eta \dot{\varepsilon}_{2}=\sigma_{2}-v\left(\sigma_{1}+\sigma_{3}\right) \\
\mathrm{E} \varepsilon_{3}+\eta \dot{\varepsilon}_{3}=\sigma_{3}-v\left(\sigma_{1}+\sigma_{2}\right) \\
\mathrm{E} \gamma_{12}+\eta \dot{\gamma}_{12}=0 \\
\mathrm{E} \gamma_{23}+\eta \dot{\gamma}_{23}=0 \\
\mathrm{E} \gamma_{31}+\eta \dot{\gamma}_{31}=0
\end{gathered}
$$

It means that, contrary to the stress-strain relations (4) in perfectly elastic solids, viscoelastic materials subjected to normal stress components may exhibit not only normal but also shear strain components (for instance after removal of a shear load).

Eqs (35) and (37) through (39) present the modified stress-strain relations in viscoelastic solids under triaxial load conditions. In what follows those in simpler load cases are listed.

$$
\begin{gathered}
\frac{\text { Plane stress }\left(\sigma_{\underline{z}}=\tau_{\mathrm{yz}}=\tau_{\underline{z x}}=0\right)}{\mathrm{E} \varepsilon_{\mathrm{x}}+\eta \dot{\varepsilon}_{\mathrm{x}}=\sigma_{\mathrm{x}}-v \sigma_{\mathrm{y}}} \\
\mathrm{E} \varepsilon_{\mathrm{y}}+\eta \dot{\varepsilon}_{\mathrm{y}}=\sigma_{\mathrm{y}}-v \sigma_{\mathrm{x}} \\
\mathrm{E} \varepsilon_{\mathrm{z}}+\eta \dot{\varepsilon}_{\mathrm{z}}=-v\left(\sigma_{\mathrm{x}}+\sigma_{\mathrm{y}}\right) \\
\mathrm{E} \gamma_{\mathrm{xy}}+\eta \dot{\gamma}_{\mathrm{xy}}=2(1+v) \tau_{\mathrm{xy}} \\
\mathrm{E} \gamma_{\mathrm{yz}}+\eta \dot{\gamma}_{\mathrm{yz}}=0 \\
\mathrm{E} \gamma_{\mathrm{zx}}+\eta \dot{\gamma}_{\mathrm{zx}}=0 \\
\sigma_{\mathrm{x}}=\frac{\mathrm{E} \varepsilon_{\mathrm{x}}+\eta \dot{\varepsilon}_{\mathrm{x}}+v\left(\mathrm{E} \varepsilon_{\mathrm{y}}+\eta \dot{\varepsilon}_{\mathrm{y}}\right)}{1-v^{2}} \\
\sigma_{\mathrm{y}}=\frac{\mathrm{E} \varepsilon_{\mathrm{y}}+\eta \dot{\varepsilon}_{\mathrm{y}}+v\left(\mathrm{E} \varepsilon_{\mathrm{x}}+\eta \dot{\varepsilon}_{\mathrm{x}}\right)}{1-v^{2}} \\
\tau_{\mathrm{xy}}=\frac{\mathrm{E} \gamma_{\mathrm{xy}}+\eta \dot{\gamma}_{\mathrm{xy}}}{2(1+v)}
\end{gathered}
$$

$\underline{\text { Plane stress }\left(\varepsilon_{\underline{z}}=\gamma_{\mathrm{yz}}=\gamma_{\underline{z x}}=0\right)}$

$$
\begin{gathered}
\mathrm{E} \varepsilon_{\mathrm{x}}+\eta \dot{\varepsilon}_{\mathrm{x}}=(1+v)\left[\sigma_{\mathrm{x}}(1-v)-v \sigma_{\mathrm{y}}\right] \\
\mathrm{E} \varepsilon_{\mathrm{y}}+\eta \dot{\varepsilon}_{\mathrm{y}}=(1+v)\left[\sigma_{\mathrm{y}}(1-v)-v \sigma_{\mathrm{x}}\right] \\
\mathrm{E}{\gamma_{\mathrm{xy}}}+\eta \dot{\gamma}_{\mathrm{xy}}=2(1+v) \tau_{\mathrm{xy}} \\
\text { and } \\
\sigma_{\mathrm{x}}=\frac{(1-v)\left(\mathrm{E} \varepsilon_{\mathrm{x}}+\eta \dot{\varepsilon}_{\mathrm{x}}\right)+v\left(\mathrm{E} \varepsilon_{\mathrm{y}}+\eta \dot{\varepsilon}_{\mathrm{y}}\right)}{(1+v)(1-2 v)} \\
\sigma_{\mathrm{y}}=\frac{(1-v)\left(\mathrm{E} \varepsilon_{\mathrm{y}}+\eta \dot{\varepsilon}_{\mathrm{y}}\right)+v\left(\mathrm{E} \varepsilon_{\mathrm{x}}+\eta \dot{\varepsilon}_{\mathrm{x}}\right)}{(1+v)(1-2 v)} \\
\sigma_{\mathrm{z}}=\frac{v\left[\mathrm{E}\left(\varepsilon_{\mathrm{x}}+\varepsilon_{\mathrm{y}}\right)+\eta\left(\dot{\varepsilon}_{\mathrm{x}}+\dot{\varepsilon}_{\mathrm{y}}\right)\right]}{(1+v)(1-2 v)}=v\left(\sigma_{\mathrm{x}}+\sigma_{\mathrm{y}}\right) \\
\tau_{\mathrm{xy}}=\frac{\mathrm{E} \gamma_{\mathrm{xy}}+\eta \dot{\gamma}_{\mathrm{xy}}}{2(1+v)}
\end{gathered}
$$


$\underline{\text { Uniaxial stress }\left(\sigma_{\underline{z}} \neq \underline{\neq}\right)}$

$$
\begin{gathered}
\mathrm{E} \varepsilon_{\mathrm{x}}+\eta \dot{\varepsilon}_{\mathrm{x}}=\sigma_{\mathrm{x}} \\
\mathrm{E} \varepsilon_{\mathrm{y}}+\eta \dot{\varepsilon}_{\mathrm{y}}=-\mathrm{v} \sigma_{\mathrm{x}} \\
\mathrm{E} \varepsilon_{\mathrm{z}}+\eta \dot{\varepsilon}_{\mathrm{z}}=-\mathrm{v} \sigma_{\mathrm{x}} \\
\mathrm{E} \gamma_{\mathrm{xy}}+\eta \dot{\gamma}_{\mathrm{xy}}=0 \\
\mathrm{E} \gamma_{\mathrm{yz}}+\eta \dot{\gamma}_{\mathrm{yz}}=0 \\
\mathrm{E} \gamma_{\mathrm{zx}}+\eta \dot{\gamma}_{\mathrm{zx}}=0
\end{gathered}
$$

and

$$
\begin{gathered}
\sigma_{\mathrm{x}}=\mathrm{E} \varepsilon_{\mathrm{x}}+\eta \dot{\varepsilon}_{\mathrm{x}} \\
\text { Shear stress }\left(\tau_{\mathrm{xy}} \neq 0\right) \\
\mathrm{E} \varepsilon_{\mathrm{x}}+\eta \dot{\varepsilon}_{\mathrm{x}}=0 \\
\mathrm{E} \varepsilon_{\mathrm{y}}+\eta \dot{\varepsilon}_{\mathrm{y}}=0 \\
\mathrm{E} \varepsilon_{\mathrm{z}}+\eta \dot{\varepsilon}_{\mathrm{z}}=0 \\
\mathrm{E} \gamma_{\mathrm{xy}}+\eta \dot{\gamma}_{\mathrm{xy}}=2(1+v) \tau_{\mathrm{xy}} \\
\mathrm{E} \gamma_{\mathrm{yz}}+\eta \dot{\gamma}_{\mathrm{yz}}=0 \\
\mathrm{E} \gamma_{\mathrm{zx}}+\eta \dot{\gamma}_{\mathrm{zx}}=0
\end{gathered}
$$

and

$$
\tau_{x y}=\frac{E \gamma_{x y}+\eta \dot{\gamma}_{x y}}{2(1+v)}
$$

As it is seen, the two-parameter Kelvin-Voigt's model of viscoelastic materials leads to relatively simple stressstrain relations. The stress-strain relations based on the three-parameter model of viscoelastic materials (spring and Maxwell's model in parallel) are given in [11].

\section{CONCLUSIONS}

The Hooke's law for multiaxial stress in elastic solids has been modified to account for damping properties of real materials.

The Kelvin-Voigt's model for viscoelastic materials has been applied to normal and shear strain components.

The viscoelastic behaviour of a homogeneous, isotropic material at a given temperature is completely defined by Young modulus E, Poisson's ratio $v$ and coefficient $\eta$ of viscous damping of normal strain.

The aforementioned constants can be determined in a uniaxial test.
It is shown that

$$
\frac{\eta}{\lambda}=\frac{E}{G}=2(1+v)
$$

where $G$ is the shear modulus and $\lambda$ is the coefficient of viscous damping of shear strain.

\section{NOMENCLATURE}

E $\quad-$ Young modulus

G $\quad-$ shear modulus

$\mathrm{t} \quad-$ time

$\mathrm{x}, \mathrm{y}, \mathrm{z}-$ three mutually perpendicular directions

$\gamma \quad-$ shear strain component

$\varepsilon \quad-$ normal strain component

$\eta \quad-$ coefficient of viscous damping of normal strain

$\lambda-$ coefficient of viscous damping of shear strain

$v \quad-$ Poisson's ratio

$\sigma \quad-$ normal stress

$\tau \quad-$ shear stress

$1,2,3$ - principal directions

\section{BIBLIOGRAPHY}

1. Lubahn J.D., Felgar R.P.: Plasticity and Creep of Metals. J. Wiley \& Sons, New York, 1961

2. Nowacki W.: Theory of Elasticity (in Polish). PWN, Warszawa, 1971

3. Panovko J.G.: Internal Friction at Vibrations of Elastic Systems (in Russian). Fizmatgiz, Moscow, 1960

4. Giergiel J.: Damping of Mechanical Vibrations (in Polish). PWN, Warszawa, 1990

5. Nashif A.D., Johnes D.I.G., Henderson J.P.: Vibration Damping. J. Wiley \& Sons, New York, 1985

6. Blake A. (Ed.): Handbook of Mechanics, Materials, and Structures. J. Wiley \& Sons, New York, 1985

7. Jakubowicz A., Orłoś Z.: Strength of Materials (in Polish). WNT, Warszawa, 1996

8. Haslach H.W., Jr., Armstrong R.W.: Deformable Bodies and Their Material Behaviour. J. Wiley \& Sons, 2004

9. Kuzmenko W.A.: New schemes of deformation of solids (in Russian). Izd. Naukova Dumka, Kiev, 1973

10.Nyashin Y., Lokhov V., Kolenda J.: On the stress-strain relations in viscoelastic solids. Marine Technology Transactions, Vol. 18, 2007, to be printed

11.Pisarenko G. S., Lebedev A. A.: Resistance of Materials to Deformation and Failure in Complex Stress State (in Russian). Izd. Naukova Dumka, Kiev, 1969.

CONTACT WITH THE AUTHOR

Prof. Janusz Kolenda

Mechanic-Electric Faculty, Polish Naval Academy Śmidowicza 69 81-103 Gdynia POLAND phone : +48 586262789 